\title{
Neutral Beam Power System for TPX
}

\author{
S. Ramakrishnan, O. Nelson Bowen, Thomas O'Connor, John Edwards, Norman Fromm, \\ Ron Hatcher, Richard Newman, Guy Rossi, Timothy Stevenson and Alfred von Halle \\ Princeton Plasma Physics Laboratory \\ P. O. Box 451, Princeton, New Jersey 08543
}

\begin{abstract}
The Tokamak Physics Experiment (TPX) will utilize to the maximum extent the existing Toknmak Fusion Test Resctor (TFTR) equipment and facilitios. This is particularly true for the TFTR Neutral Beam (NB) system. Most of the NB hardware, plant facilities, suxiliary sub-systems, power systems, service infrastructure, and control systems can be need as is. The major chenges in the NB handware are driven by the new operating duty cycle. The TFTR Neutral Beam was designed for operation of the Sources for 2 seconds every 150 ceconds. The TPX requires operation for 1000 seconds every 4500 reconds. During the Conceptual Design Phase of TPX every component of the TFTR NB Eloctrical Power System was analyzed to verify whether the equipment can moet the new operational requirements with or without modifications. The Power System converts $13.8 \mathrm{kV}$ prime power to controlled pulsed power required at the NB cources. The major equipment involved are circuit breakers, ato and rectifier transformers, surge suppression components, power letrodes, HV Decks, and HVDC power transmission to sources. Thermal models were developed for the power transformers $\omega$ simulate the new operational requirements. Heat runs were conducted for the power tetrodes to verify capability. Other components were analyzed to verify their thermal limitations. This paper describes the details of the evaluation and redesign of the electrical power system components to meet the TPX operational requirements.
\end{abstract}

\section{INTRODUCTION}

The Neutral Beam System (NBS) for TPX consists of a single beamline with three (3) Ion Sources that deliver a wotal of $8 \mathrm{MW}$ to the plasma for a pulse duration of 1000 seconds at one pulse per 75 minutes, for a maximum of 10 pulses in 24 hours. Each Ion Source has an independent power supply system capable of being operated from a Local Control Center or remotely from the Central Instrumentation Control And Data Acquisition System (CICADA) System.

The Neutral Beam Power System is composed of electrical and mechanical systems that convert the $13.8 \mathrm{kV}$ prime power to controlled pulsed or continuous power at the output of the power system as required for the various elements of the ion sources and auxiliaries.

Each Primary Power Subsystem (PPS) has a lowimpedance dc power output designed to provide good voltage regulation for the accelerating and gradient grids of each ion source. The function of the PPS is to convert the fixed frequency AC Power to the controlled dc power for the Modulator/Regulator (M/R). This subsystem consists of primary power selector switches, Fast Vacuum Intermupter (FVI), voltage selector (Autotransformer), and high voltage transformer rectifier, which are located in the NB Switchyard, and a Surge Room with crowbar and capacitor banks located inside the NB Power Conversion (NBPC) Building . From the Surge Room the power is fed to the Accel and Gradient Grids of each of the Ion Sources via the (M/R), also located in the NBPC Building.. The M/R employs a series High Voltage Switch Tube (high powered Tetrode) in a floating deck design. Power transmission from the $M / R$ to the Ion Sources is accomplished using a High Voltage Deck (HVD) and a Transmission line from the HVD to the Ion Sources.

Other power supplies include those for Arc, Filament and Decel Grid of each Ion Source. In the TFTR there are twelve Ion Sources installed capable of delivering $34 \mathrm{MW}$ to the Plasma. It is proposed to use three of the Sources for TPX . The Electrical Power System will be reconfigured and modified to feed the three Ion Sources to meet the TPX operating scenarios.

\section{DESCRIPTION AND CHANGES}

The majority of the NB power components are usable for TPX with appropriate modifications and reconfiguration to achieve the thermal capability required for long pulse operation. Each component of the Electrical Power System was analyzed to verify whether the new operational requirements can be met. The One Line diagram of the Accel Power System is shown in Fig. 1. The principal concern was the thermal capability of the Autotransformer and the Rectifier Transformer. Thermal models for the transformers were developed and based on simulation studies it was decided to operate two units in parallel for each of the Sources. The other area of concern was the M/R High Voltage Tetrode which was successfully tested and $\mathrm{CW}$ operation was demonstrated. The Following describes the major power system components and details of any modifications required to meet the TPX operational scenario.

\section{AC Power:}

The AC Power for the major load of Accelerating Grids is received at the Fast Vacuum Interrupter (FVI) via $3-1 / \mathrm{c} 500 \mathrm{mcm}$ feeder cables [6]. The power requirement is $34.5 \mathrm{MVA}$ from the $13.8 \mathrm{kV}$ bus. At present one set of $500 \mathrm{mcm}$ cables feed three sources. For the TPX machine an additional 3-1/c $500 \mathrm{mcm}$ cables will be provided to feed three sources in order to meet the new thermal capability requirements. The existing provision to select power from two different buses will be retained.

The auxiliary loads (total of $0.59 \mathrm{MVA}$ ) consisting of Decelerating Grid, Arc, Magnet, and Filament are fed from 480 Volt buses. No changes are required for these feeds.

\section{Fast Vacuum Interrupter}

The FVI is used to disconnect the NBPS from the prime power source in the event of a fault in the secondary 
of the HV transformer-/rectifier or output load. An ' upstream AC breaker will open if a fault occurs between the FVI and the HV transformer-rectifier primary.

The existing breaker is 500 MVA, 1200 Amps, (23 kA interrupting rating, $37 \mathrm{kA}$ Momentary). The breaker is adequately rated for TPX operation, after taking into consideration that the crowbar current is doubled to approximately 6000 Amps symmetrical at tap 12 of the Auto transformer, the highest proposed operating level for TPX. The buswork from the FVI to the auto transformer is also adequately rated.

One FVI will be connected to feed two Autotransformers. The connections will be such that the other FVI will be on standby. See Fig. 1 for details.

\section{Voltage Selector (Autotransformer)}

The voltage selector is a seventeen (17) position tapped autotransformer rated at 2.4 MVA (CW) equipped with a motorized tap changer, and housed in an oil filled convection cooled tank. The controller provides adjustment capability for the PPS output voltage through the range of $30 \mathrm{kV}$ dc to $150 \mathrm{kV} \mathrm{dc}$. Currently on TFTR there are twelve such units in use, with one additional unit as spare. The parallel connections are shown in Fig. 1.

The thermal capability of the Autotransformer has been analyzed and documented per Ref. 4. Fig. 2 gives the thermal model. Thermal simulation of the Autotransformer using the model indicates that the duty cycle imposed for the TPX operating scenario will result in increased temperature of the series winding. In order to meet the increased thermal capability requirements for the longer pulses in TPX, two auto-autotransformers will be connected to feed one Source. Thus six autotransformers will be used for feeding three Sources.

\section{HV Transformer-Rectifier}

The HV transformer-rectifier is of a 2.24 MVA (CW, Impedance of $8.5 \%$ at 11.9 MVA base) unit with a three (3) winding power transformer on a single iron core with a Wye connected primary and two secondaries of which one is connected in Wye and the other in Delta. Two rectifier transformers will be connected to feed one source for TPX in order to meet the thermal requirements. The rectifier part of each rectifier-transformer consists of two 3-phase full wave bridges connected in cascade for 12 pulse operation, giving a voltage output of $167 \mathrm{kV}$. The HV transformer-rectifier assembly is contained within a single oil-filled tank located outdoor next to the NB Power Conversion Building.

There are thirteen units at PPPL including one spare. Three are aluminum wound coils and the rest are copper wound. Thermal capability of the rectifier-transformer has been analyzed and documented per Ref. 5 . The thermal model for the rectifier-transformer is simular to that for the autotransformer (see Fig. 2) with changes to include three windings and rectifier losses. The thermal simulation indicates that the unit may withstand the 1000 second pulses every 3500 seconds from the point of view of average temperature rise. However, the primary winding of the transformer has a high current density $\left(7000 \mathrm{~A} / \mathrm{in}^{2}\right)$ and is likely to develop high hot spot temperatures.

Hence, for the TPX system the output of the two rectifier-transformers will be connected in parallel to feed one Source. A two conductor High Voltage DC (HVDC) cable will be installed from one surge room to the other to accomplish parallel configuration. Initial review of the transformer impedances indicate that load sharing of the parallel paths will be within 5\%. Testing is required to verify proper operation.

\section{Surge Room (Transient Suppression \& Crowbar)}

During the turn-on of a Neutral Beam pulse, transient energy must be supplied to enhance the rise timi. A $6 \mu \mathrm{F}$ capacitor bank is incorporated at the HVDC output of the rectifier transformer and will store $85 \mathrm{~kJ}$ at $168 \mathrm{kV}$ (open circuit voltage) for this purpose. A resistor is connected in series with the capacitor bank in order $t 0$ match the system and reduce voltage transients during turm-on or tum-off.

A high speed crowbar is connected to the output of the capacitor bank to divert fault energy from the ion source and HV Switch Tube (in the Modulator/Regulator). The crowbar design is based on the use of ignitrons. Crowbar firing will take place within 2 to 3 microseconds of detecting a fault. The crowbar must handle the charge stored in the capacitor bank (about 1 coulomb) as well as that drawn from the primary lines until the FVI opens and disconnects the system. The existing crowbar is designed to draw 20 coloumbs from the primary lines.

With parallelled transformers the crowbar ignitron chains of each of the two surge rooms will also be connected in parallel. Under the conditions of failure of one parallel path the second path must handle all the charge. Data on the ignitrons (National Electric NL-37248) used in the crowbar circuits indicates that the ignitrons with enhanced water cooling will meet the requirements.

\section{Modulator/Regulator (M/R)}

The key component in the $M / R$ is the High Voltage Switch Tube, RCA No. $\$ 94000$ E, manufactured by RCA. The tube is designed for two megawatts of continuous plate dissipation. In the TFTR application the tube has operated reliably at one MW dissipation on a pulsed mode of two seconds every one hundred-fifty seconds. However, the low mass construction of the unit indicates that steady state thermal equilibrium is reached in less than a second. To verify this assumption, a one-hour, trip-free test at one megawatt (the power nominal required for TPX operation) was siccessfully conducted at the Burle facility.

The only major component of the $M / R$ that requires modification for the TPX operating conditions is the Gradient Grid Resistor, which is a tapped voltage divider that provides a voltage to the ion source gradient grid. Under consideration is a water cooled resistor assembly or a floating Gradient Grid Power Supply proportional to the accel voltage.

With a few minor exceptions, all other structural, electrical and control components of the Mod-Reg equipment can be used as is for TPX. 


\section{Arc and Filament Power Supplies}

The Arc power supply must be capable of supplying $100 \mathrm{~V}, 1200 \mathrm{~A}$ continuously and $160 \mathrm{~V}, 1200 \mathrm{~A}$ for the initial ten seconds of each 1000 second pulse. The Filament power supply must be capable of supplying 10 $V, 3200 \mathrm{~A}$ continuously and $15 \mathrm{~V}, 5500 \mathrm{~A}$ for the initial ten seconds of each 1000 second pulse. The components of the existing supplies will be retained with the exception of the three winding isolation transformers, the Variable Voltage Transformers (VVTs), and the High Voltage Enclosure (HVE).

The existing $120 \mathrm{kV}$ isolation transformers are not capable of operation for the long pulse length. The new transformers will be of open frame construction, eliminating the need for the existing HVE. In addition, tapped inductors will be procured to replace the VVTs.

Improvements to the existing system will include a closed loop feedbeck system to control the waveshape and response characteristics, harmonic cancellation filters to reduce ac harmonics, and L-C filters to reduce dc output voltage ripple.

\section{Magnet Power Supply}

The existing power supplies for the magnet are suitable for TPX.

\section{Decel Power Supply}

The Decel supply is being operated far below it's nameplate rating of $3 \mathrm{kV}, 20 \mathrm{~A}$ (continuous). Again, TPX operations will change only the pulse length, not the voltage and current requirements. The existing Decel supply will be used as is with minor modification to the cooling system to improve tube socket heat dissipation.

\section{High Voltage Deck}

High Voltage Decks (HVDs) for the proposed TPX Neutral Beam Systems are to be located in the Neutral Beam Power Conversion building, adjacent to their associated Modulator/Regulators and Surge Rooms. The new configuration will be an air-atmosphere design, rather

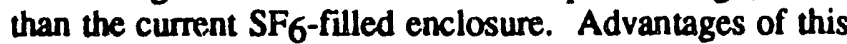
configuration include improved and expedited access and testing of components. Existing Arc and Filament dc supplies and telemetry will be utilized. Modifications will include new isolation transformers, dc filters, and insulating deck support structure.

Ion Source protection equipment presently housed in the HVEs in the Test Cell Basement will be relocated to a position near the NB Ion Sources in the Test Cell.

\section{Transmission Line}

The transmission line is the pathway by which energy from the Neutral Beam Power Conversion System is fed to each NB Ion Source, three of which are mounted on each Beamline located in the Tokamak Test Cell. The transmission line contains cables for Accel, Gradient Grid, Arc, Filament, and Instrumentation. All conductors in the transmission line are referenced at the Accel voltage (120 kV) maximum). Water cooled hollow conductors are used for Arc and Filament.

A $12^{\text {" }}$ aluminum tubular enclosure will be utilized for the transmission line conductors. All conductors will be insulated by SF6, an insulating gas, at 1 atm gauge. The tube walls will be sized to support a vacuum of 300 mtorr for leak checking as well as the 1 atm of SF6. A spacerguide, fabricated of G-10 fiberglass or similar material, will be utilized approximately every 4 feet throughout the transmission line to locate the high current conductors within the enclosure and to counteract the electromagnetic forces acting on these conductors.

The lines will be run under the floor from the highvoltage deck in the NBPC building to the Ion Source in the Tokamak Test Cell. Existing floor and wall penetrations will be utilized. A special section of the line containing the Ion Source Protection Equipment (ISPE) will be located below each ion source in the Test Cell. The new location of the snubbers in the ISPE further minimizes the fault energy to the ion source. Also, the transmission line will terminate in new electrical connections designed to facilitate source installation and repair.

\section{Instrumentation and Control}

The Neutral Beam Injection System (NBIS) has an extensive Instrumentation and Control (I\&C) system for the power equipment consisting of local power control centers, magnet controllers, source fault detection equipment, and timing controls. The beam power is also interlocked to the plasma discharge monitor, the machine state monitor, the beamline temperature scanning system, and the programmable controllers for the beamline and gas injection subsysems. Also, a summation of the individual source powers is transmitted through the beamline power monitor in real time to the plasma control system. The I\&C system is interfaced to the computer system through digital and analog input/output modules, multichannel digitizers, timing modules, and remote consoles and displays. For TPX the existing I\&C system can be used virtually as is with minor changes to add a link interface to the upgraded computer system.

The NBIS also has an extensive personnel and equipment safety system consisting of Kirk Key interlocks, emergency stops, test cell door interlocks, and hardwired power system status displays and permissives. All of these safety features can be retained as is for the TPX program.

\section{CONCLUSION}

Suitability of the various TFTR Neutral Beam power system components for TPX application has been established by engineering analysis, thermal modeling and/or actual testing. Thermal capacity for the TPX operating scenario has been achieved by rearrangement of the power equipment. The primary changes are paralleling the Accel HV Power Supply components, reconfiguration of the High Voltage Deck, and a new transmission line. Thus the majority of TFTR Neutral Beam power system 
equipment can be used for the TPX Machine with minor ' changes, modifications and/or reconfiguration.

\section{ACKNOWLEDGMENT}

This work was supported by US DOE Contract No. DE-ACO2-76-CHO3073.

\section{REPERENCES}

[1] "System Description - Neutral Beam Power Supply" TFTR-SDD-8B

[2] "OLTC Autotransformer - Operation, Service, and Maintenance Manual" TRANSREX No. A20-046786
[3] "Transformer Rectifier - Operation, Service, and Maintenance Manual" TRANSREX No. A20-046787

[4] "Thermal Analysis of the NB Autotransformer" Report \# 21-930217-PPPL-NFSR-02

[5] "Thermal Analysis of the NB Rectifier Transformer" Report \# 21-930217-PPPL-NFSR-01

[6] C. Neumeyer, et al "TPX Power Systems Design Overview"15th SOFE Conference paper 5-PA-24

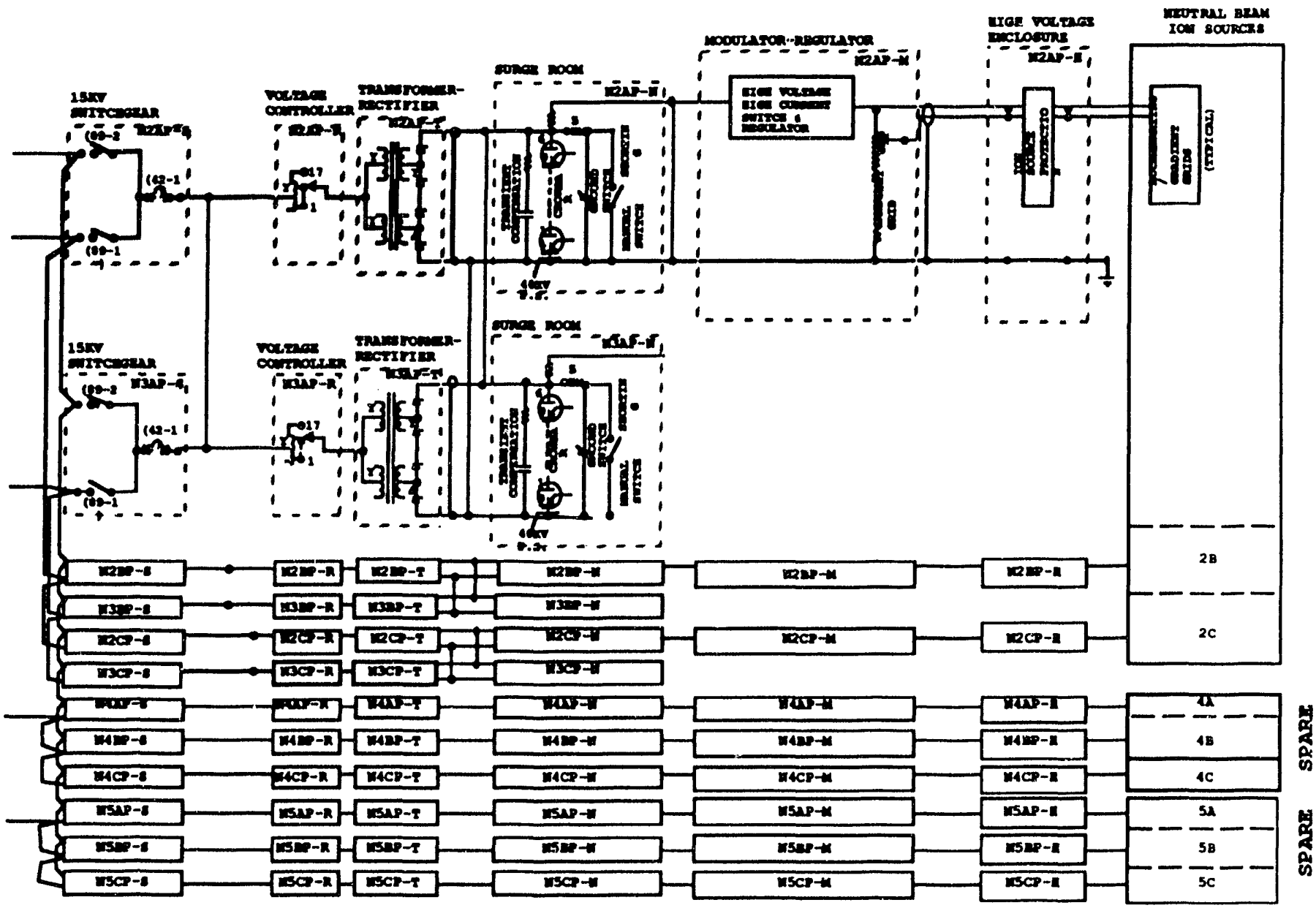

Figure 1 : Neutral Beam Power Supply One Line Diagram for Acceleration Grid Systems - Ion Sources

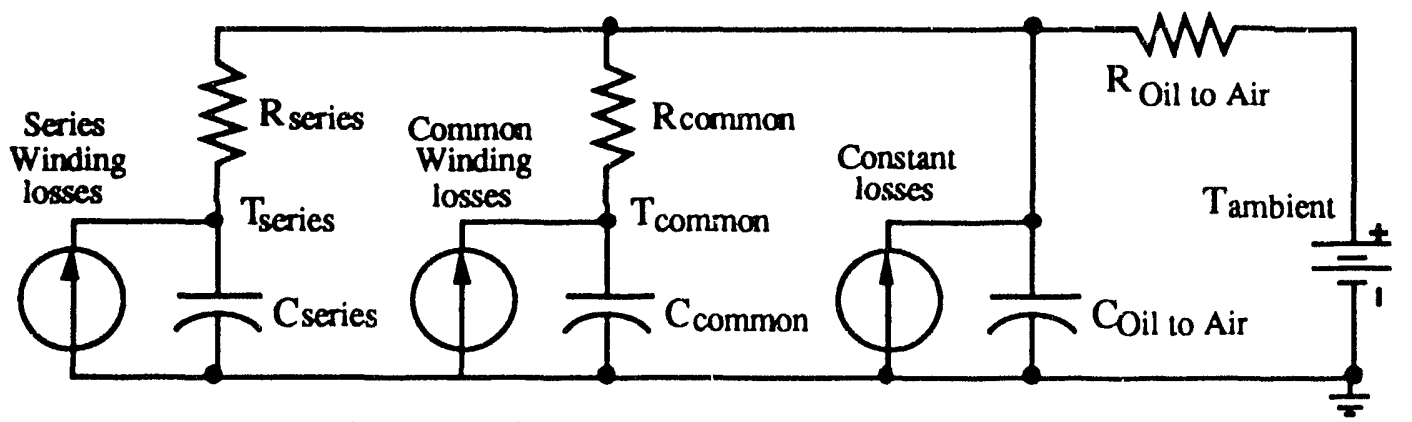

Figure 2: Thermal Model of the Autotransformer

The $C \& R$ values are Thermal Capacitance Watthours/ degree $C$ and Thermal Resistance degree C/Watt respectively 


\section{DISCLAIMER}

This report was prepared as an account of work sponsored by an agency of the United States Government. Neither the United States Government nor any agency thereof, nor any of their employees, makes any warranty, express or implied, or assumes any legal liability or responsibility for the accuracy, completeness, or usefulness of any information, apparatus, product, or process disclosed, or represents that its use would not infringe privately owned rights. Reference herein to any specific commercial product, process, or service by trade name, trademark manufacturer, or otherwise does not necessarily constitute or imply its endorsement, recommendation, or favoring by the United States Government or any agency thereof. The views and opinions of authors expressed herein do not necessarily state or reflect those of the United States Government or any agency thereof. 


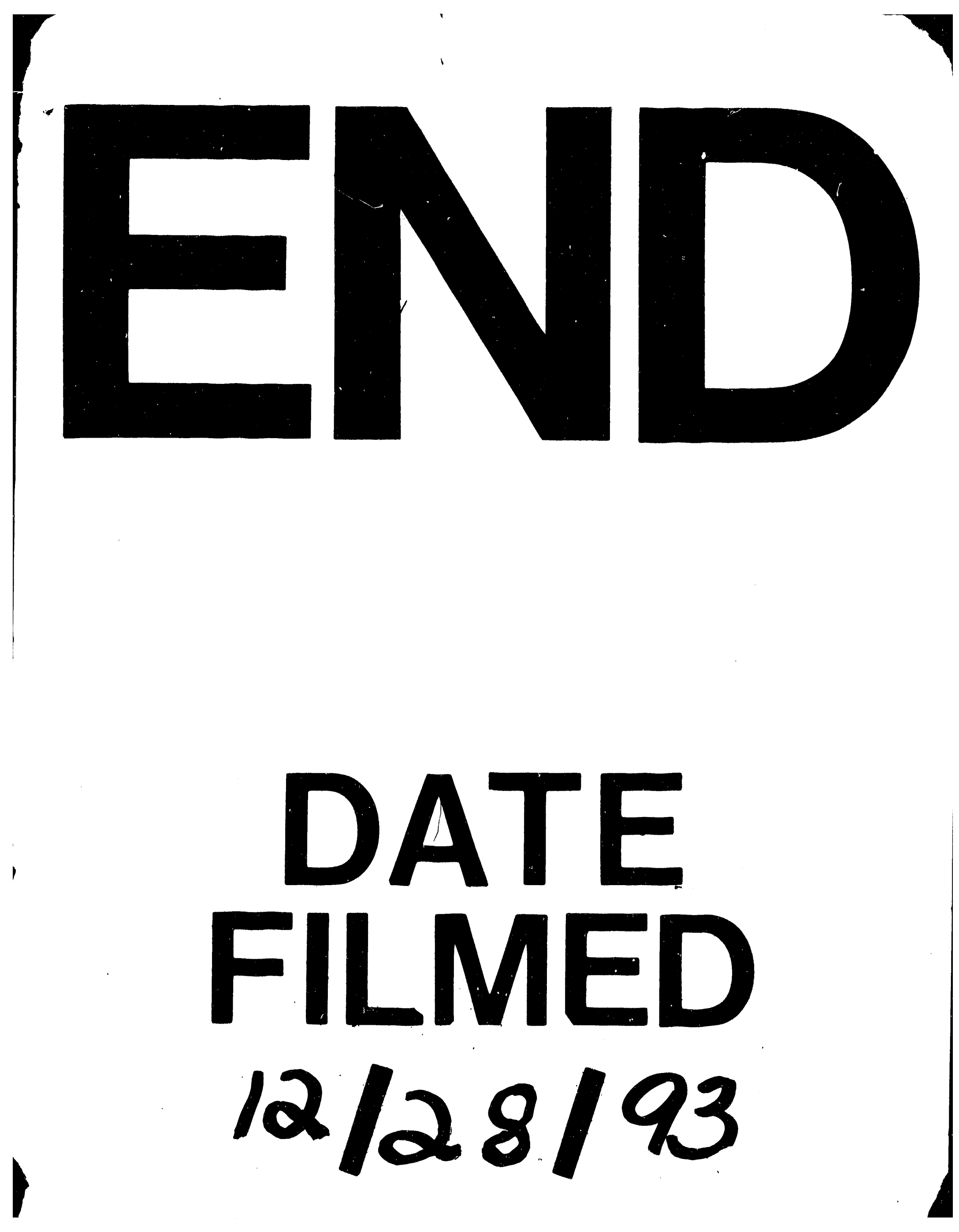




\section{1}

